\title{
Elevated Water Tank
}

\author{
B.Venkat NarsimhaRao, Shree Mahalakshmi, Dhrama TEJA, P.Santhosh
}

\begin{abstract}
Water tanks are the capacity booths for putting away water. Raised water tanks are built to be able to deliver required head with the purpose that the water will movement affected by gravity the development exercise of water tanks is as antique as enlightened guy. The water tanks project has an firstrate want as it serves ingesting water for amazing populace from exceptional metropolitan urban groups to the little population dwelling in cities and towns.

The smaller than ordinary project is led for a time of 15 days to have total all the way right down to earth information on unique tactics and issues appeared within the field. An change issue like construction factors, layout Parameters, information of Formwork, information of aid, process of Water treatment Plant and Execution had been controlled over the span of our smaller than regular undertaking. "improved water tanks" via raising water tank, the enlargement upward push makes a conveyance strain at the tank outlet.
\end{abstract}

The profile of water tanks begins offevolved with the utility parameters, consequently the type of materials applied and the form of water tank become directed by way of approach of those factors:

1. Vicinity of the water tank (inner, out of doors, over the floor or underground).

2. Volume of water tank need to preserve.

3. What the water may be utilized for?

Four. Temperature of territory wherein might be located away, fear for solidifying.

Five. Weight required conveying water.

6. How the water to be conveys to the water tank.

7. Wind and quake plan contemplations allow water tanks to endure seismic and excessive wind occasions.

\section{INTRODUCTION}

Potential materials and overhead tank are applied to store water, fluid oil, oil primarily based commodities and similar fluids. The strength research of the substances or tanks is prepared the identical no matter the concoction concept of the item. All tanks are deliberate as break up unfastened structures to wipe out any spillage. Water or crude oil retaining segment and dividers can be of fortified cement with remarkable spread to the assist. Repositories underneath the floor level are commonly labored to keep wonderful quantities of water even though the ones of overhead kind are worked for direct circulate thru gravity move and are for the most part of littler restrict.

For potential of big amount of liquids like water, oil, oil, corrosive and in some unspecified time inside the future

B.Venkat NarsimhaRao, Assistant Professor, Department of Civil Engineering, Siddhartha Institute of Technology and Sciences, Hyderabad,

Shree Mahalakshmi, Assistant Professor, Department of Civil Engineering, Siddhartha Institute of Technology and Sciences, Hyderabad, Telangana, India.

Dhrama TEJA, Assistant Professor, Department of Civil Engineering, Siddhartha Institute of Technology and Sciences, Hyderabad, Telangana, India.

P.Santhosh, Assistant Professor, Department of Civil Engineering, Siddhartha Institute of Technology and Sciences, Hyderabad, Telangana, India.
Revised Manuscript Received on September 14, 2019. Telangana, India.

gases likewise, carafes or tanks are fundamental. These structures are organized of know-how, steel, metallic-clad present and pre-centered on concrete. Out of those, brick artwork and steel tanks are applied for minor sizes. The tempo of metallic tanks is remarkable and therefore they're no longer genuinely carried out for water stockpiles Reinforced strong tanks are real widespread in mild of the fact that, other than the structure and configuration being fundamental, they are minimal strive, sizeable in nature and may be made spillage affirmation.

For the most element, no accidents are accepted to arise in any phase of the shape of Liquid maintaining RCC tanks and they're made water fitted by means of way of making use of extra extravagant mixture (now not $>$ M 30) of cement. What is more, now and again water sealing belongings moreover are utilized to make tanks water geared up. Ability of water within the association of tanks for consuming and washing functions, pools for exercise and a laugh and sewage sedimentation tanks are purchase increasing importance within the go with the float day existence.A water tank is utilized to stock water to hold over the every day requirements. Raised tanks are upheld on technology which may also encompass of stone art work dividers, RCC sections supported together, counter dividers exposed to water stress. In water supply conspire, water tanks for the maximum part represent $10 \%$ to $20 \%$ of the all out price. That is truly massive quantity and subsequently, there may be a essential to perform minimum attempt in improvement of water tanks. The mountain for capacity of amazing quantity of drinks like water, oil, oil, corrosive and sooner or later gases likewise, jars or tanks are primary.

\section{1 category OF R.C.C. TANKS}

In like way they'll be categorized in 3 types depending upon the location.

- $\quad$ Tanks laying on ground.

- $\quad$ Tanks over the ground stage (expanded tanks).

- Underground tanks.

\subsubsection{FLUIDS stored IN steel TANKS}

Tanks can be full or void right now of sadness in some unspecified time in the future of activities of commonplace dangers. The substance of those tanks is sizeable due to the fact that it could avoid top notch sadness of the shell contingent upon the quantity and on the physical homes of the fluid.

\section{Thickness and express gravity}

The thickness of the fluid is its mass consistent with unit volume. Water has a thickness of one $\mathrm{gm} / \mathrm{cm} 3$ at $4^{\circ} \mathrm{C}$. The thickness of a fluid assumes a huge task within the shape of a tank, thinking about that large densities require thicker 
shells. Express gravity is some other widespread physical property of the fluid placed away. It's miles a percentage of the general load of one fluid contrasted with water. In specific, it's far the proportion of the thickness of the fluid remoted through the thickness of the water at $15.5^{\circ} \mathrm{C}$. As an instance, oil, lamp oil and fuel have a particular gravity of 0. Eighty, zero.Eighty and 0.70 for my part. Care need to be practiced if there may be a noteworthy increment inside the particular gravity of the brand new fluid in moderate of the reality that the compelling hydrostatic weight following up at the tank dividers is probably more outstanding if the shape diploma is not reduced, and could reason damage at the round and hollow shell.

\section{Fume weight and breaking aspect}

The fume weight of an unadulterated fluid is the burden of the fume vicinity over the fluid in a near compartment, and increments with expanding temperature. It's miles a large notion for you to pick the shape of tank and its rooftop and is pivotal to give an explanation for hearth peril. The breaking factor is also huge. It's far vital to understand the temperatures at which some fluids have to be placed away, continuously beneath its breaking element. For instance, some combustible and flammable fluids are confined through using the fire codes to be placed away at temperatures over their breaking element. Endless tanks observed across the island of Puerto Rico are possessed through petroleum treatment facilities or petrochemical groups, and shop combustible fluids.

\section{Weight}

Weight is characterized as electricity consistent with unit area. In the usa, the architects jogging on this subject normally use crawls of water phase or ouncesconsistent with rectangular creeps to particular the estimation of weight or vacuum in the fume area of a tank, in slight of the truth that the weights are normally low comparative with environmental weight. As indicated by way of this weight the architect must decide the splendid and in this manner thickness of the tank. For each barrel fashioned and spherical shells, the maximum mind boggling a few portion of the tank to configuration is the intersection a number of the rooftop and the chamber in slight of the truth that few situations might also seem: (a) whilst the weights rule on the chamber, the rooftop avoids to go together with the lower shell; (b) whilst there is an inner weight that surpasses the heaviness of the plates and encircling of the rooftop, this intersection will in huge wreck unfastened the shell. The difference of weight among in the tank, its fume area, and the close by barometric weight (environmental weight) is called the internal weight. On the factor at the same time as this weight is bad, it's miles referred to as a vacuum. At the off danger that a tank has an interior weight surpassing the estimation of a hundred $\mathrm{KN} / \mathrm{m}^{2}$ comparative with barometrical weight, they're delegated pressure vessels and are secured by the code for "Kettle and strain Vessels" of ASME (American Society of Mechanical Engineers). Such instances are past the volume of this paintings. For a barometrical tank, the improvement of a vacuum in the inner moreover brings about outside weight. Outdoor weights can be amazingly harming to tanks due to the reality their surface zones are massive and this produces high powers. The inordinate outside weight brings about clasping of the shell dividers or absolute breakdown.

\subsection{Three category dependent on the inward weight}

For the situation that an inward weight follows up at the tank during ability, it's miles capacity to signify those tanks primarily based on this diploma of weight. This weight effect relies upon straightforwardly of the scale of the tank. The bigger the tank, the more critical effect of weight is at the shape. This grouping is normally used by codes, models and guidelines anywhere in the course of the world.

Barometrical tanks: these tanks are the most well-known. Despite the reality that they are known as air, they are usually labored at inner weight as a substitute above air strain. The fireplace codes signify an air tank as running from air up to 3 .Five $\mathrm{KN} / \mathrm{m} 2$ above climatic weight.

Low-stress tanks: within the placing of tanks, low weight means that tanks are intended for a weight higher than air tanks. This likewise implies those tanks are normally excessive-pressure tanks. Tanks of this type are presupposed to paintings from air stress as a whole lot as round a hundred $\mathrm{kN} / \mathrm{m} 2$.

Weight vessels (immoderate-stress tanks): in view that high-pressure tanks are absolutely strain vessels, the time period excessive-stress tank is not commonly utilized; as a substitute they're referred to as simply vessels. Since those kinds of tanks are commonly assembled underground, they will be excluded from this artwork and they're not canvassed in detail on this discourse. In any case, they may be handled independently from wonderful tanks thru all codes, gauges, and pointers.

\subsection{4 classification of top notch tank segments}

There isn't any number one approach to arrange tanks depending on a solitary foundation, for instance, its form or rooftop. Anyways, this model is easier than some exclusive one due to the fact tanks are ordered uniquely with the aid of seen notion. The shape is normally dictated via the substance. The fume weight of the substance positioned away or inward plan pressure is the broadest and maximum generally applied approach acquired by using codes, gauges and guidelines, as clarified previously. Subsequently, the fume pressure comes to a decision the form and, thusly, the form of tank implemented. Those huge tank segments include the general kingdom of the tank and the rooftop form itself.

\section{THE ROOF OF A TANK \& METHODOLOGY}

The country of the rooftop is a helpful pointer of the type of tank given that it is very obvious to the writer tanks, fabricator and erector. Different types of rooftop Fixedrooftop tanks, cone fashioned rooftop, umbrella-rooftop tanks, tank Dome rooftop, Aluminum geodesic vault rooftop tanks, skimming rooftop tanks. 


\subsection{Five Cylinder}

Most tanks have a tube fashioned frame, that is applied as a ability extent. Some are framed by a chamber, as regarded in Figure 1 and 1.4. The dividers may have a steady thickness or reduced dividers with diverse traits of thickness at diverse statures. Smooth external floor of the tank and this is the area the inward surface thickness modifications were watched. Weld nice is widespread for the uprightness of the shell, and some disappointments had been accounted for that starts on the weld at the bottom of the shell. Some have a rooftop tank with out wind brace ring is welded outwardly; guide may have a thickness of the request for $7 \mathrm{~mm}$ with a width that may go someplace inside the range of one hundred and 2 hundred mm. Another tank has an unbending ring to stop neighborhood clasping of the shell below the weight of the breeze. At closing, there's a tank with a few rings constantly dispersed, as appeared in Figure 1.6.

\subsubsection{Tank Bottoms}

Another full-size part of the tank is a base fabricated from welded metal plate. In the research, the tanks are normally displayed as fixed to the ground, so it's miles whatever however an difficulty to understand the correct country of the base. Be that as it may, for architects this standpoint is big in light of the fact that numerous conditions wherein a base of the tank may be charged. A fundamental tank may be comprehensively delegated degree or cone shaped base.

\subsection{Foundations Of Tanks}

This phase applies to tank considered in this research, ie spherical and hollow tank with a level base continually strengthened. A website online geotechnical considers required within the plan of the status quo; However, by using and big (specially for tanks located in the seaside the front territory) of land prone to having a uniform or differential settlement. The sort of status quo may be separated into a few characterizations in through and huge increasing request of value.

Established order minimized soil, squashed stone ring divider established order, solid ring divider established order, status quo bite, status quo Pile-upheld

\subsection{Objectives}

- To make an research of the examination and plan of water tanks.

- To make an investigation of the policies for the plan of fluid conserving systems as consistent with the IS Code.

- To find out increasingly more about the plan reasoning for sheltered and economic structure of water tanks.

- To create packages for the plan of the water tank of an adaptable base and unbending base and underground tanks to stay away from repetitive figurings.

- In the end, this system is authorized by the effects of manual computations given inside the book Concrete Structures.

\section{PHILOSOPHY}

\subsection{Introduction}

raised tank structure is generally used to store water for residential physical activities and moreover the reason for the neighborhood organization of hearth-fighters. Their well-being execution is a considerable problem at some point of a strong tremor. There are a few examinations in which the dynamic behavior of the fluid stockpiling tank has been broke down, but the widespread majority of them have focused on the dirt surface barrel formed tank, and no longer a lot of them had been focused on the conduct of a raised tank. They are overwhelming structures that the greater a part of their body weight is focused on the peak of a enormous part of the basis. Because of the high affectability of the raised water tank with substance tremor attributes, as an instance, recurrence, maximum intense ground increasing speed and the a hit term of the quake statistics, truly wishes to reflect the seismic burden as a non-desk bound arbitrary example.

\subsection{Failure Mode}

Modus tank damage is as according to the following:

1) Bend the aspect dividers

2) Failure pinnacle of the tank and their crossing factors three) Sliding and lifting

four) neighborhood damage at the base of the tank and uneven settlement

five) Failure of stay jolts

6) Cracking the annular bit of the base plate

Portrayal.
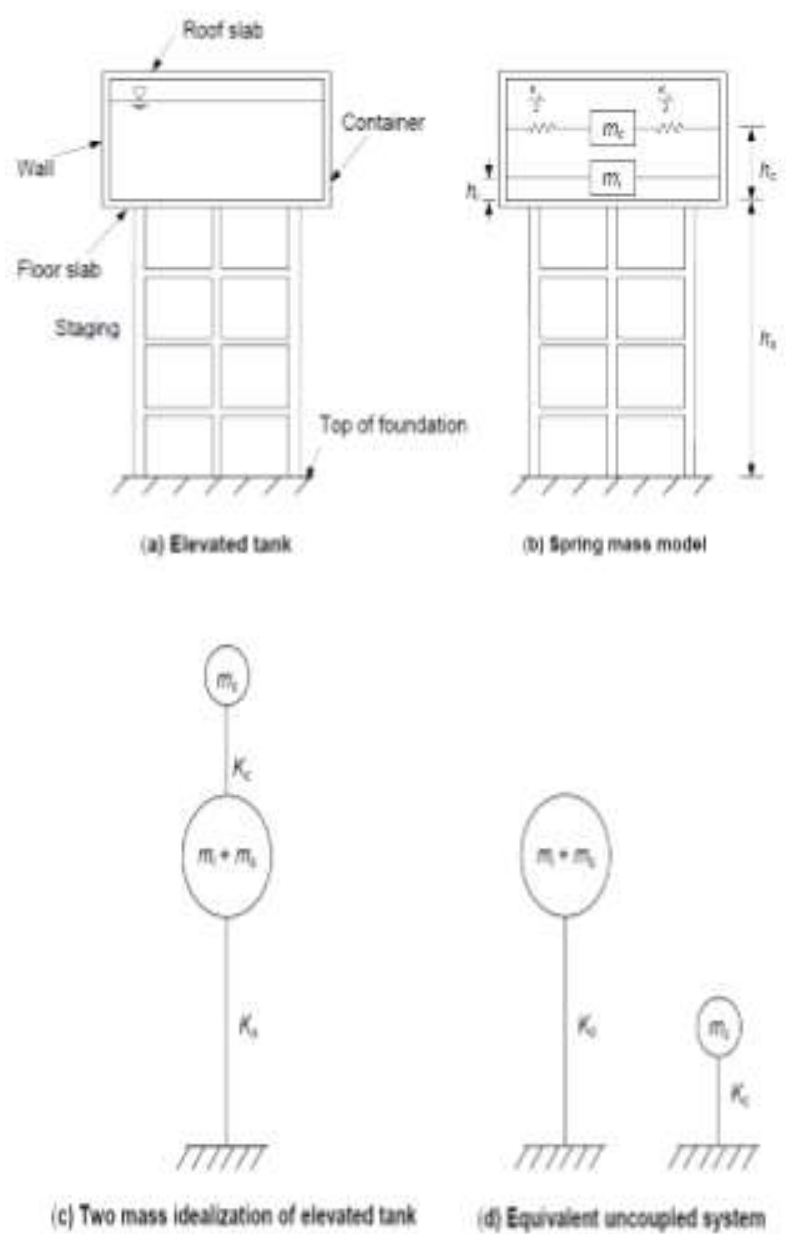

(c) Two mass idealization of elevated tank

Figure 3.5: Two Mass Idealization of Elevated Tank

Published By: Blue Eyes Intelligence Engineering 
For raised tanks with minute opposing type outline arranging, the parallel firmness can be assessed via pc exam or by means of essential techniques or via built up auxiliary research method.

Parallel firmness of the arranging is the even energy required to be achieved at the point of interest of gravity of the tank to motive a comparing unit flat dislodging. The adaptability of propping bar might be taken into consideration in computing the sidelong solidness, Ks of raised minute opposing side type tank organizing.

3.Four The essential elements That have an effect on the significance Of Earthquake Forces Are-

\section{(a) Seismic region factor, $Z$}

India has been remoted into 4 seismic zones in keeping with IS 1893 (part 1): 2002 for the most taken into consideration Earthquake (MCE) and control lifestyles of the form in a sector. One-of-a-kind area have numerous place trouble. Discern three. 6 indicates seismic region guide of India. India is remoted into 4 seismic zones. There are 3 styles of soil taken into consideration via IS 1893 (part 1): 2002 as an example delicate medium and tough soil.

\section{(b) importance component, I}

Importance difficulty is primarily based at the useful usage of the systems, defined with the aid of risky effects of its disappointment, post-seismic tremor practical desires, chronicled esteem, or monetary significance. Raised water tanks are utilized for putting away consumable water and deliberate for disaster administrations, as an instance, taking off fires administrations and are of submit-seismic tremor importance. Consequently, significance thing is 1.5 for raised water tank.

\section{(c) response decrease component, $R$}

Reaction lower issue is primarily based upon the plain seismic damage execution of the form, defined by means of pliable or prone misshapenings. R estimations of tanks aren't as a good buy as running due to the truth that tanks are typically much less bendable and function low more at the same time as contrasted with constructing. For outline asserting to bendy itemizing as an example precise minute opposing casing (SMRF), $\mathrm{R}$ esteem is 5 .

\section{(d) Structural reaction detail, $(\mathrm{Sa} / \mathrm{g})$}

It's miles a difficulty signifying quickening response variety of the shape exposed to seismic tremor floor vibrations, and is based upon commonplace time of vibration and damping of the form.

Three.5 goal of the look at

The precept goal of this research is to have a have a look at the nodal elimination of accelerated round tube customary water tank upheld on define arranging considering various stature and sector and plotting the diagrams as max. Nodal uprooting Vs tallness and max. Nodal elimination Vs region.

\section{6 functionality of Staad-pro programming}

STAAD.Pro.V8i is the maximum frequent auxiliary constructing programming item for 3-D model age, investigation and multi-material plan. It has a herbal, smooth to apply GUI, example apparatuses, floor-breaking research and plan places of work and regular turning into a member of to 3 different demonstrating and shape programming gadgets. For static or dynamic exam of scaffolds, law systems, hooked up structures (passages and guides), pipe racks, metal, sturdy, aluminum or timber structures, transmission towers, arenas or some one of a kind essential or complicated shape, STAAD .Seasoned has been the choice of plan professionals round the world for his or her specific investigation goals.

Three.7 Modeling of Water tank

For this examination, water tanks with 5 notable statures, for instance, $5 \mathrm{~m}, 10 \mathrm{~m}, 15 \mathrm{~m}, 20 \mathrm{~m}$ and $25 \mathrm{~m}$ are considered, and every water tank is installed quarter 2 , three, 4 , and five. The effect of statures of tank and tremor zones on nodal removal is visible with the assist of research of 20 fashions having equal parameters.

Here the seismic coefficient method is finished for the water tank by using the product bundle deal STAAD seasoned. It's miles likewise essential to pick out the quality feasible component kind and determine employ route. Here line additives are utilized for showing the hoop bar, propping, section and location additives (Plate) are applied for pinnacle arch, base segment, and barrel common divider.

Three. 8 Steps pursued for displaying the organizing and tank compartment STAAD-pro:

1) Modeling geometry: here water tank geometry is model by using manner of using framework.

2) define element kind: right here part kind factor is carried out for top ring shaft, base ring bar, assisting, phase and territory issue (plate) is carried out for pinnacle arch, base chunk, and tube shaped divider.

Three) define fabric residences: right here we offer the homes of the pillar and plate, as an example,

Flexible modulus, Poisson's percentage, mass thickness, compressive exceptional and so forth

4) define phase houses: Prismatic square shape regions characterize the width and profundity for

Ring pillar, base ring shaft, propping and kaleidoscopic circle represent the width for segment.

5) Seismic Definition: In seismic definition pick out kind of code, represent area, reaction

Kind of soil, form of structure, damping proportion, and hooked up order profundity and so forth

6) observe burdens and restriction condition: define menu offers choice to indicating the restrict conditions and masses.

7) Base Shear outcomes: The association is acquired utilizing the exhibit alternative in essential menu.

\section{RESULTS AND DISCUSSIONS}

4.1 Results obtained from STAAD PRO analysis: 


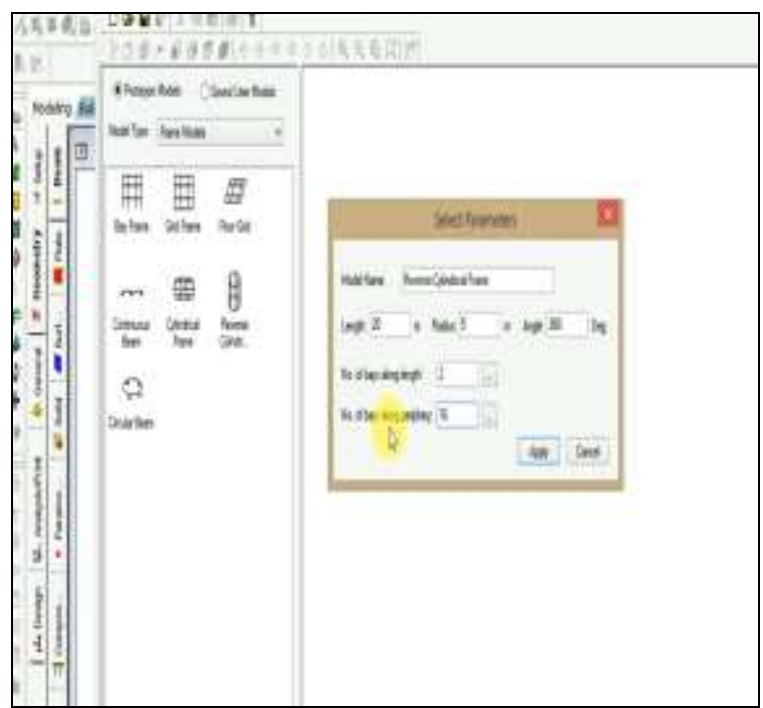

Fig 1: selecting frame using geometry

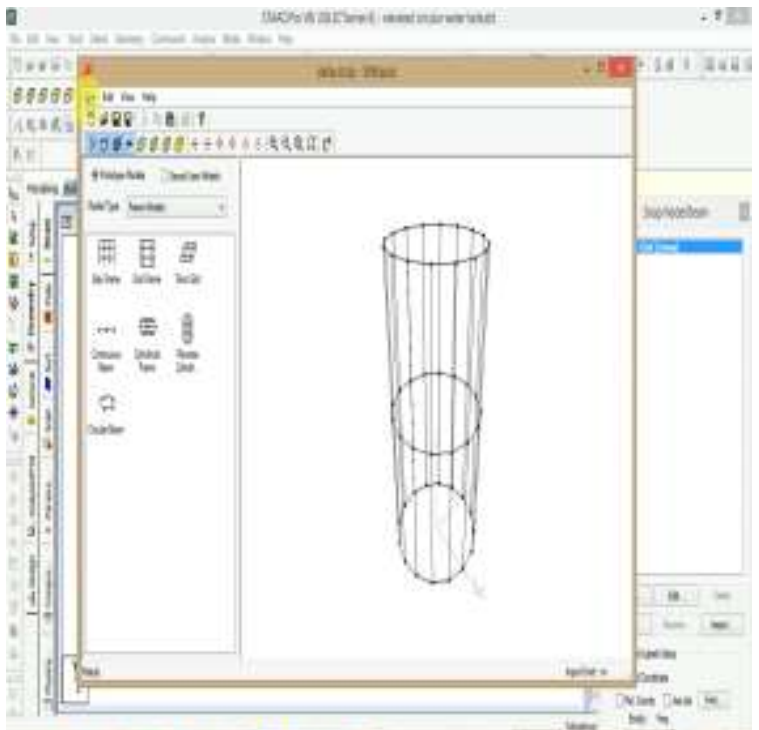

Fig 2: generated cylinder

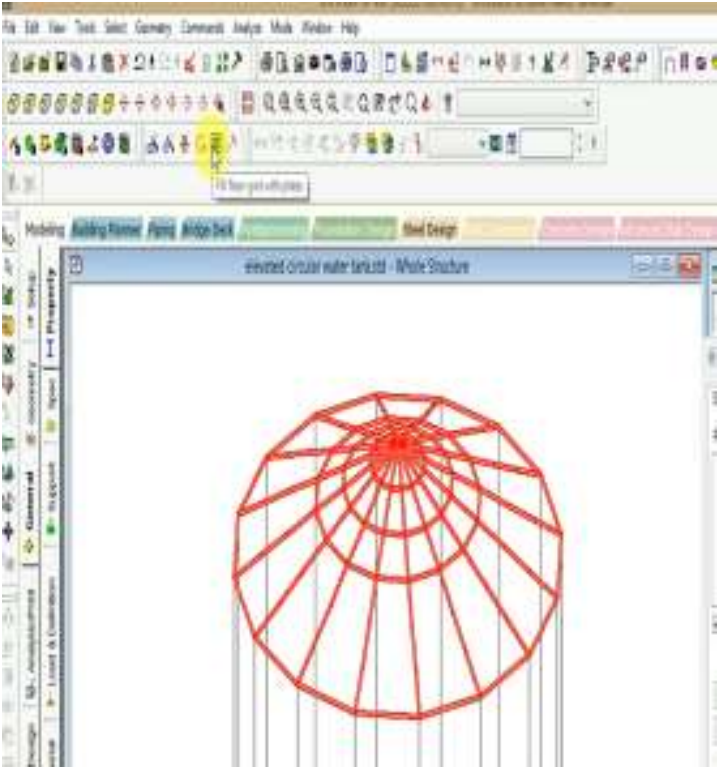

Fig 3: grids filled with floor plates

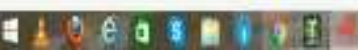

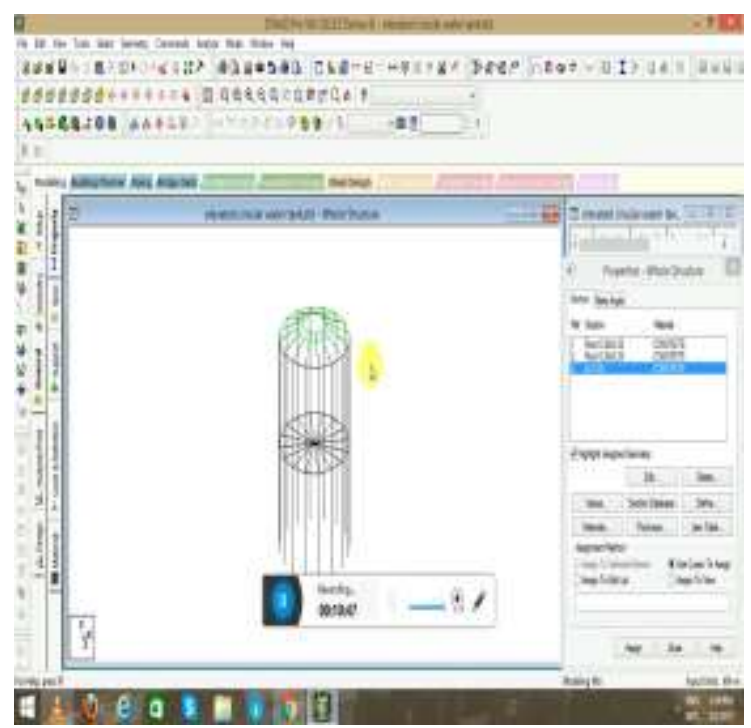

Fig 4: properties to be assigned

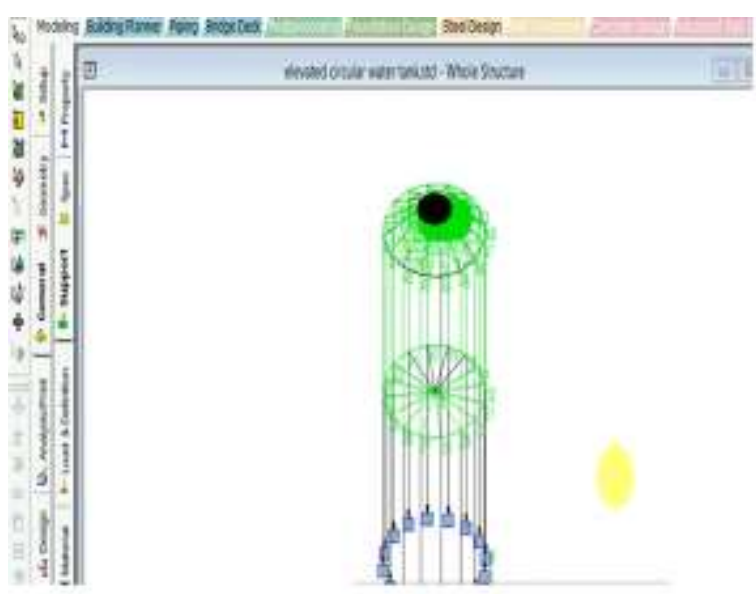

Fig 5: fixed supports assigned to the structure

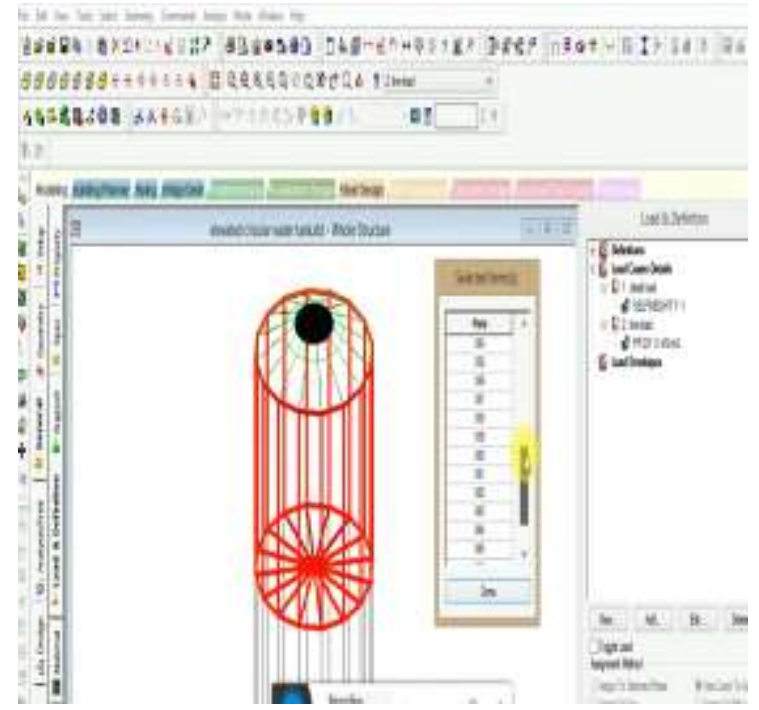

Fig 6: assigned loads

Published By:

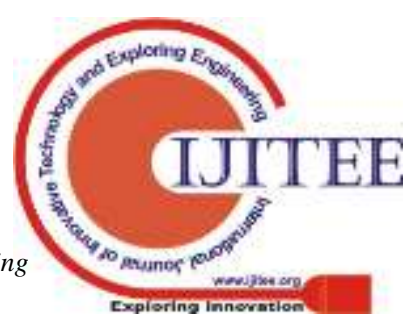




\section{ELEVATED WATER TANK}

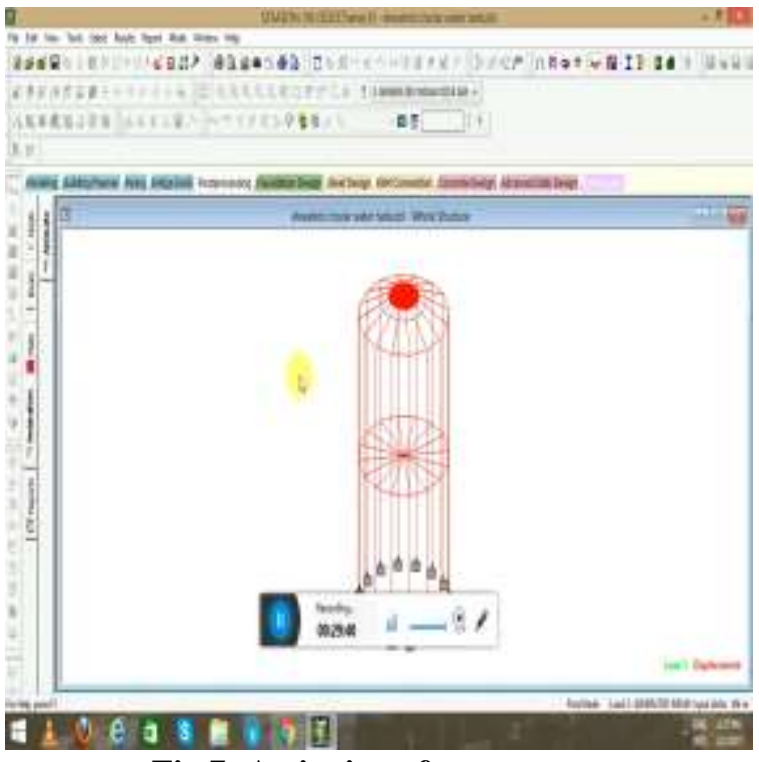

Fig 7: Assigning of parameters

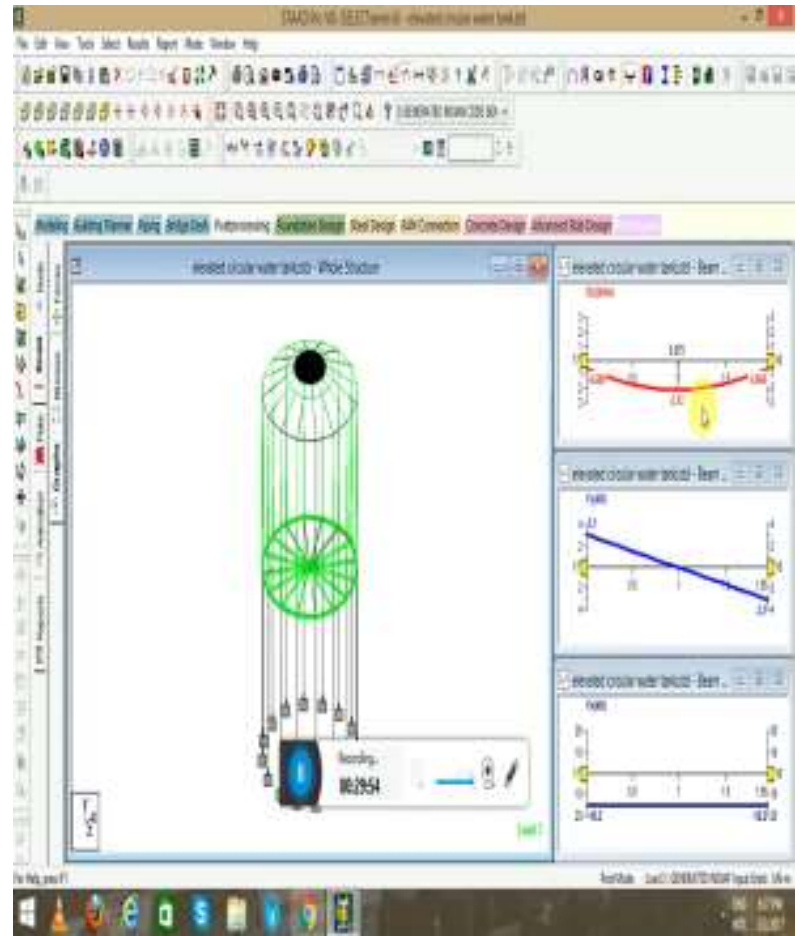

Fig 8: Final result of elevated water tank

\section{CONCLUSIONS}

- Design of the water tank is a method of bleak. Especially the plan to raise the water tank round and perforated covers many numerical formulation and estimates. It's too dull. Furthermore Staad - Professional affords all the results, for example, shear, revocation nodal and so on direct exam.

- As the tallness of constructing a water tank max. Gradual abolition of nodal.

- At the top of each one of the models of the investigation, the most intense nodal deletion is as a minimum

- Present concentrates will be treasured for expertise the behavior of Civil Engineers raised the water tank.

\section{REFERENCE}

1. Gaikwad, M.V. (2013). "Examination of the static and dynamic research of the water tank raised". Worldwide Journal of Civil Engineering and Technology, 4 (3), 2043-2052.

2. Gaikwad, M.V. (2013). "Execution of the Circular Increased seismic Water Tank with Framed Staging". Universal Journal of reducing aspect checking of Engineering and Technology, 4 (four), 159-167.

3. Hirde, S., Bajare, A. Also, Hedaoo, M. (2011) "Execution seismic raised from the water tank". Global Journal of Advanced Engineering Research and Studies, 1 (1), 78-87.

4. IITK-GSDMA (2007). "Rules for the seismic structure of fluid retention tank", the National Information Center of Earthquake Engineering, IIT Kanpur.

5. IS :- 1893-1984 "Criteria for Earthquake Resistant Design of Structures", Bureau of Indian Standards, New Delhi.

6. IS: 1893 (Part-1) - 2002. "Criteria for Earthquake Resistant Design of Structures", Bureau of Indian Standards, New Delhi.

7. IS: 1893 (Part 2) - 2002 "Criteria for Earthquake Resistant Design of Structures Part 2 Maintaining Liquid Tank", Bureau of Indian Standards, New Delhi.

8. IS: 11682 - 1985 "Criteria for Design Of Rcc Staging For Overhead Water Tank", Bureau of Indian Standards, New Delhi.

9. Jaiswal, O.R., Jain, S.K. (2005). "Changed endorse preparations for seismic tank fluid retention plan: Part I placing codal". Diary of Structural Engineering, 32 (three), 195-206.

10. Jaiswal, O.R, and Jain, S.K. (2005). "Adjusted proposed arrangements for fluid retention tanks seismic structure: Part II - discourse and version". Diary of Structural Engineering, 32 (4), 297-310.

11. Jain, S.K., and Sajjad, S.U. (1993). "A Review of India's needs inside the code for seismic structure of the water tank Elevated". Bridges and simple technique, 12 (1), 115. [12] Ekbote, S.P. (2013). "Seismic Behavior of RC lifting water tank underneath a wide range of set layout". Diary of Engineering, Computer and Applied Science, 2 (8), 23-29. 